\title{
The therapeutic effect of the neuropeptide hormone somatostatin on Schistosoma mansoni caused liver fibrosis Shyama Chatterjee*1, Gunther Vrolix ${ }^{1}$, Inge Depoortere ${ }^{2}$, Theo Peeters ${ }^{2}$ and Eric Van Marck ${ }^{1}$
}

Address: ${ }^{1}$ Laboratory of Pathology, Faculty of Medicine, University of Antwerp, Universiteitsplein-1, B-2610 Antwerp, Belgium and ${ }^{2}$ Laboratory of Gastrointestinal Hormones, Gasthuisberg, Leuven, Belgium

Email: Shyama Chatterjee* - Shyama.Chatterjee@ua.ac.be; Gunther Vrolix - Gunther.Vrolix@ua.ac.be; Inge Depoortere - inge.depoortere@med.kuleuven.ac.be; Theo Peeters - theo.peeters@med.kuleuven.ac.be; Eric Van Marck - eric.van.marck@uza.be

* Corresponding author

Published: 10 June 2005

BMC Infectious Diseases 2005, 5:45 doi:10.1 186/I47|-2334-5-45
Received: 30 December 2004

Accepted: 10 June 2005

This article is available from: http://www.biomedcentral.com/I47I-2334/5/45

(c) 2005 Chatterjee et al; licensee BioMed Central Ltd.

This is an Open Access article distributed under the terms of the Creative Commons Attribution License (http://creativecommons.org/licenses/by/2.0), which permits unrestricted use, distribution, and reproduction in any medium, provided the original work is properly cited.

\begin{abstract}
Background: The neuropeptide somatostatin is one of the major regulatory peptides in the central nervous system and the digestive tract. Our recent work has delineated an association between fibrosis and low levels of endogenous somatostatin plasma levels in Schistosoma mansoni infected subjects. Based on these results this paper explores the therapeutic potential of somatostatin in a mouse model of hepatic fibrosis associated with S. mansoni infections.
\end{abstract}

Methods: Groups of outbred Swiss mice were infected with $100 \mathrm{~S}$. mansoni cercariae, infection maintained till weeks 10 or 14 , and then somatostatin therapy delivered in two regimens - Either a one or a two-day treatment. All animals were sacrificed one week after therapy and controlled for liver, spleen and total body weight. Circulating somatostatin levels in mice plasma were measured at the time of sacrifice by means of a radio-immuno assay. GraphPad Prism ${ }^{\circledR}$ was used for statistical calculations.

Results: Somatostatin administration showed little toxicity, probably due to its short half-life. Total liver and spleen weights of $S$. mansoni infected animals increased over time, with no changes observed due to somatostatin therapy. Total body weights were decreased after infection but were not affected by somatostatin therapy. Snap frozen liver sections were stained with haematoxylineosin or Masson's trichrome to study parasite count, hepatocyte status, granuloma size and cellularity. After somatostatin treatment mean egg counts per liver section $(43.76 \pm 3.56)$ were significantly reduced as compared to the egg counts in untreated mice after 10 weeks of infection $(56.01 \pm 3.34)(P=0.03)$. Similar significant reduction in parasite egg counts were also observed after somatostatin treatment at 14 weeks of infection $(56.62 \pm 3.02)$ as compared to untreated animals $(69.82 \pm 2.77)(P=0.006)$. Fibrosis was assessed from the spectrophotometric determination of tissue hydroxyproline. Infection with $S$. mansoni caused increased hydroxyproline levels $(9.37 \pm 0.63 \mu \mathrm{mol}$ at wk $0 ; 9.65 \pm 0.96 \mu \mathrm{mol}$ at wkl4) as compared to uninfected animals $(\mathrm{I} .06 \pm 0.10 \mu \mathrm{mol})$. This significant increase in collagen content $(P=0.0 \mathrm{I} ; 0.007$ respectively) marks the fibrosis observed at these time points. Treatment with somatostatin resulted in a significant decrease in hydroxyproline levels both at wk $10(4.76 \pm 0.58 \mu \mathrm{mol})$ and at wk $4(5.8 \pm 1.13 \mu \mathrm{mol})$ $(P=0.01 ; 0.03$ respectively). Endogenous somatostatin levels were increased at wk $10(297 \pm 37.24$ 
$\mathrm{pg} / \mathrm{ml})$ and $\mathrm{wk} \mathrm{I} 4(206 \pm 13.30 \mathrm{pg} / \mathrm{ml})$ of infection as compared to uninfected mice (I I $9 \pm \mathrm{I} \mathrm{I} .99 \mathrm{pg} /$ $\mathrm{ml})(P=0.0 \mathrm{I} ; 0.008$ respectively). Circulating somatostatin levels in infected animals were not significantly affected by somatostatin treatment. Hepatocyte status remained unaltered and granulomas were not remarkably changed in size or cellularity.

Conclusion: Our experiments reveal an antifibrotic effect of somatostatin in schistosomiasis. We have previously shown that the somatostatin receptors SSTR2 and SSTR3 are present on the parasite egg and worms. We therefore hypothesize that somatostatin reduces either the number of parasite eggs or the secretion of fibrosis inducing-mediators. Our data suggest somatostatin may have therapeutic potential in S. mansoni mediated liver pathology.

\section{Background}

Somatostatin (SOM) or somatostatin-14, a 14 amino acid peptide hormone was originally isolated from the hypothalamus. It was soon after reported in the central nervous system (CNS), the stomach, gastrointestinal (GI) tract and pancreas. By 1980, the gene coding for prosomatostatin had been identified and two molecular forms (SOM-14 \& SOM-28) were reported. As the five specific receptors for somatostatin (SSTR1-SSTR5) belonging to the G proteincoupled receptor family were identified, it became clear that the different molecular forms and various receptors are part of a complicated control system that regulate a variety of body functions. Somatostatin exerts profound inhibitory functions not only on growth hormone secretion but also on many GI functions. These different aspects form the basis for the therapeutic potential of somatostatin in various diseases [1].

Somatostatin alone or in combination with endotherapy has been successfully used in the management of bleeding esophageal varices (BOV) [2]. Following an acute bleeding episode somatostatin is administered over a period of 5 days and acts by reducing the splanchnic blood flow. Somatostatin is useful in reducing peptide ulcer bleeding and the lack of recurrence [3]. More recently, somatostatin has also shown proven benefits in the management of pancreatic disorders, such as pancreatic fistulae, acute pancreatitis and the prevention of complications following pancreatic surgery [4-6]. Somatostatin is well tolerated, with very few side effects.

Complications resulting from hepatic fibrosis are the principal cause of death in Schistosoma mansoni infected patients [7]. In such patients portal hypertension leads to the formation of gastro-esophageal collaterals (varices). Fatal bleeding of these esophageal varices can occur depending on the severity of fibrosis. We have previously shown an association between severe hepatic fibrosis and low levels of endogenous somatostatin [1]. Taking these reports into consideration, our present study was aimed to test the therapeutic capacity of exogenously administered somatostatin on S. mansoni caused liver pathology.
In schistosomiasis the principal inflammatory response is directed against the parasite eggs some of which enter the portal circulation, become lodged in hepatic portal venules initiating a granulomatous response. During periovular granuloma formation fibronectin produced by macrophages is deposited around the inflammatory cells $[8,9]$ composing a large part of the extracellular matrix. This is followed by the deposition of the proteoglycans dermatan sulphate, to a lesser extent heparan sulphate [10], and the interstitial collagen types I \& III that all together form the fibrotic tissue.

Collagen is composed of three chains, wound together in a tight triple helix (Fig. 1.). A repeated sequence of three amino acids forms this sturdy structure. Every third amino acid is glycine, a small amino acid that fits perfectly inside the helix. Many of the remaining positions in the chain are filled by two unexpected amino acids: proline and a modified version of proline, hydroxyproline. The glycine forms a tiny elbow packed inside the helix, and the proline and hydroxyproline smoothly bend the chain back around the helix.

Our recent studies have elucidated the presence of somatostatin receptors (SSTR2A, mostly associated with inflammatory cells, and receptor SSTR3 expressed in the liver) on $S$. mansoni egg and worm stages (manuscript submitted). Soluble egg antigen (SEA) secreted by the egg stage parasite in the liver triggers inflammation and fibrosis [11]. Circulating host somatostatin levels might inhibit SEA production via interaction with the SSTR receptors on the parasite surface, thereby regulating the level of liver fibrosis and as a result portal hypertension, variceal bleeding and fatality due to this disease. In related studies the group of Reynaert [12] have shown that the presence of SSTRs 1, 2 and 3 on hepatic stellate cells could be used as therapeutic targets for reducing fibrosis in chronic liver disease because treatment with somatostatin decreased collagen I and III and alpha-SMA synthesis.

Based on these reports we presented the hypothesis that exogenous administration of somatostatin could alleviate the pathology caused by schistosomiasis. To prove this we 


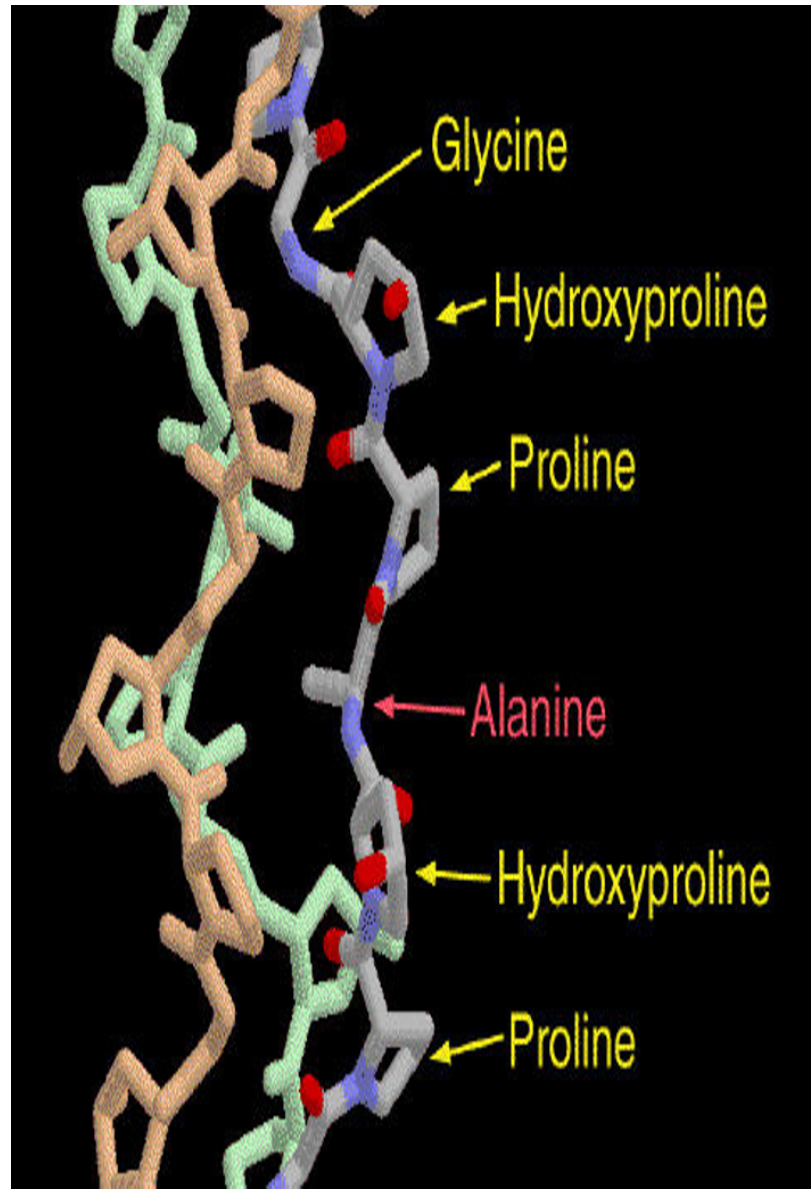

Figure I

Structure of collagen triple helix.

tested the effect of somatostatin treatment on collagen deposition in the liver of Schistosoma mansoni infected Swiss mice as compared to control uninfected or untreated mice. We have on several occasions stressed the therapeutic potential of somatostatin on $S$. mansoni caused liver fibrosis [13]. Our results may indicate an endogenous function of the somatostatin receptors on the parasite surface and point to their role in host-parasite interactions.

\section{Methods}

\section{Pharmacokinetic profile of somatostatin}

Separate groups of male Swiss mice were injected with 25 $\mu \mathrm{g}$ of somatostatin (somatostatin-ucb ${ }^{\oplus}$, UCB Pharma, Brussels) intraperitoneally (in the abdomen) or intravenously (in the caudal vein in the tail). At defined moments after injection (10, 20, 40, 60 minutes) the animals were anaesthetized with $\mathrm{Nembutal}^{\oplus}(60 \mathrm{mg} / \mathrm{kg})$. The thoracic cavity was cut open and blood collected from the right ventricle of the heart into chilled syringes containing EDTA $(1 \mathrm{mg} / \mathrm{ml})$ and Aprotinin (500 KIU/ml blood). The collected blood was centrifuged at $3000 \mathrm{rpm}$ for $15 \mathrm{~min}-$ utes at $0^{\circ} \mathrm{C}$. The plasma was immediately frozen at $-80^{\circ} \mathrm{C}$ freezer. Untreated naïve mice were also bled to ascertain background levels of somatostatin.

\section{Schistosoma mansoni infection}

The maintenance of the $S$. mansoni life cycle and the transcutaneous infection of mice with $S$. mansoni have been previously described [14]. Male Swiss mice (age 7 weeks) were anaesthetized with $\mathrm{Nembutal}^{\circledR}(60 \mathrm{mg} / \mathrm{kg})$ and the abdomen was shaved. A metal ring was placed on the abdomen and then filled with treated water containing infectious cercariae of a Puerto Rican strain of S. mansoni. The cercariae were allowed to penetrate during 20 minutes after which the water was removed and checked for remaining cercariae.

\section{Experimental setup}

Groups of Swiss mice were infected with 100 S. mansoni cercariae each as mentioned above. Age matched mice were maintained as uninfected control animals. Groups of 10 mice composed Group 1 that were maintained till 10 weeks following infection, other 10 mice composed Group 2 that were maintained till 14 weeks of infection.

At such times animals of Groups 1 and 2 were treated with somatostatin (Somatostatine-ucb ${ }^{\circledR}$ ), that was kindly gifted by UCB Pharma, Brussels. Somatostatin was administered in two regimens - a one-day treatment or a two-day treatment. One day treatment consisted of 3 doses of $30 \mu \mathrm{g}$ somatostatin each, two day treatment was the double of this dose, that is 6 doses of $30 \mu \mathrm{g}$ somatostatin to each animal. Somatostatin was administered intravenously via the caudal vein in the tail and intraperitoneally at regular intervals during the day. One week after the last somatostatin administration, mice were killed, the weight of the animal, liver and spleen were noted, plasma was extracted and stored as mentioned above, and the liver frozen immediately in liquid nitrogen and then at $-80^{\circ} \mathrm{C}$. The overall planning is depicted in Table 1. Untreated animals of the acute and chronic stage were also sacrificed at the respective times together with their treated counterparts. Research protocols involving rodents received ethical clearance by the University of Antwerp ethical committee.

\section{Parasite egg count and hepatocyte status after somatostatin treatment}

All animals of Groups I and II were controlled for liver, spleen and total body weight, before sacrifice. The adult worms were recovered from the hepatic portal system and the liver by perfusion with citrate saline $(0.85 \%$ sodium chloride; $1.5 \%$ sodium citrate). The livers were cut out and snap frozen in liquid nitrogen. For cyosectioning, 
Table I: The experimental planning of our study is depicted.

\begin{tabular}{|c|c|c|c|c|c|c|}
\hline Criteria & Gp I & Gp I & Gp I & Gp 2 & Gp 2 & Gp 2 \\
\hline $\begin{array}{l}\text { Time of SOM } \\
\text { treatment }\end{array}$ & $\begin{array}{l}\text { Acute (wk. I0) I } \\
\text { day treatment }\end{array}$ & $\begin{array}{l}\text { Acute (wk. I0) } 2 \\
\text { days treatment }\end{array}$ & $\begin{array}{l}\text { Acute (wk. I0) } \\
\text { Untreated }\end{array}$ & $\begin{array}{l}\text { Chronic (wk. I4) I } \\
\text { day treatment }\end{array}$ & $\begin{array}{l}\text { Chronic (wk. I4) } 2 \\
\text { days treatment }\end{array}$ & $\begin{array}{l}\text { Chronic (wk. I4) } \\
\text { Untreated }\end{array}$ \\
\hline No. doses & $\begin{array}{l}3 \times 30 \mu g(2 \times I P \\
I \times I V)\end{array}$ & $\begin{array}{l}6 \times 30 \mu g(4 \times I P ; \\
2 \times I V)\end{array}$ & NA & $\begin{array}{l}3 \times 30 \mu g(2 \times I P \\
I \times I V)\end{array}$ & $\begin{array}{l}6 \times 30 \mu g(4 \times I P \\
2 \times I V)\end{array}$ & NA \\
\hline Total SOM & $90 \mu g$ & $180 \mu g$ & NA & $90 \mu g$ & $180 \mu g$ & NA \\
\hline
\end{tabular}

NA: not applicable; SOM: somatostatin ${ }^{\circledR}$; Wk.: week; IP: Intraperitoneal; IV: Intravenous; No.: number.

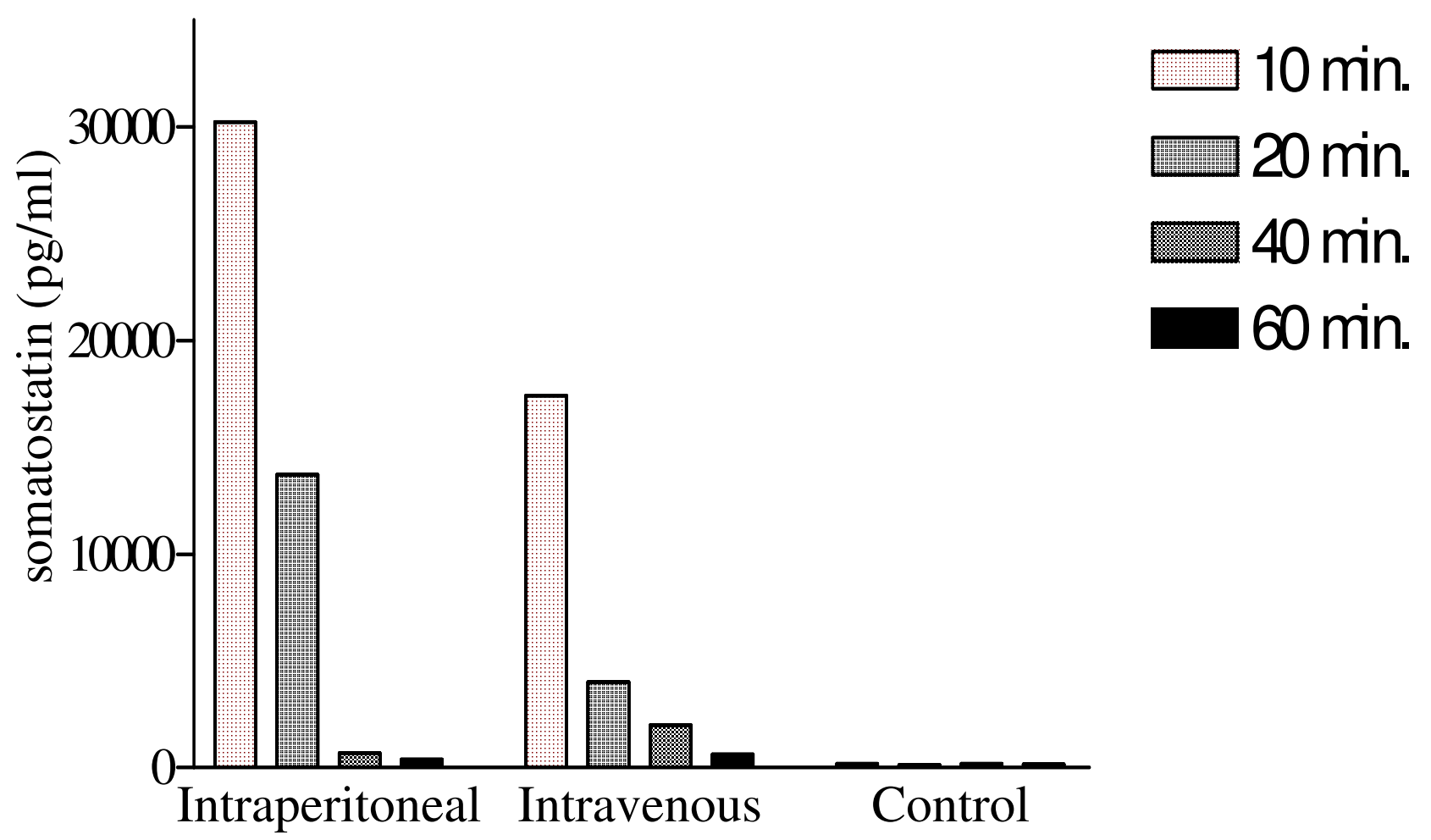

Figure 2

Pharmacokinetic profile of somatostatin in Swiss mice. Figure depicts the breakdown of somatostatin in vivo after intraperitoneal and intravenous administrations. Values were noted after 10, 20, 40 and 60 minutes and compared to a control situation where no somatostatin was administered.

liver fragments were embedded in Tissue-Tek OCT compound, $4 \mu \mathrm{m}$ thick transverse sections were cut on a cryostat, mounted on slides coated with $0.1 \%$ ploy-L-lysine and stored at $-20^{\circ} \mathrm{C}$ until use. To study parasite egg count, hepatocyte status, granuloma size and cellularity, series of sections were stained with Haematoxylin-eosin stain.

\section{Hydroxyproline determination}

The collagen concentration was determined by assessing hydroxyproline amount. Herein is described the protocol of Technique $\mathrm{B}$ for the biochemical assessment of fibrosis used by Bergman and Loxley [15]. Just as was done by Cheever [16] we neutralized our samples for the color reaction.

\section{Reagents used}

1. Dowex/Norit: Twenty mg of Dowex (Sigma, St. Louis, Missouri, US) and $10 \mathrm{mg}$ Norit A (Merck, Darmstadt, Germany) were mixed together in $200 \mathrm{ml}$ of $6 \mathrm{~N} \mathrm{HCl}$. The Dowex/Norit mixture was recovered with the help of a 


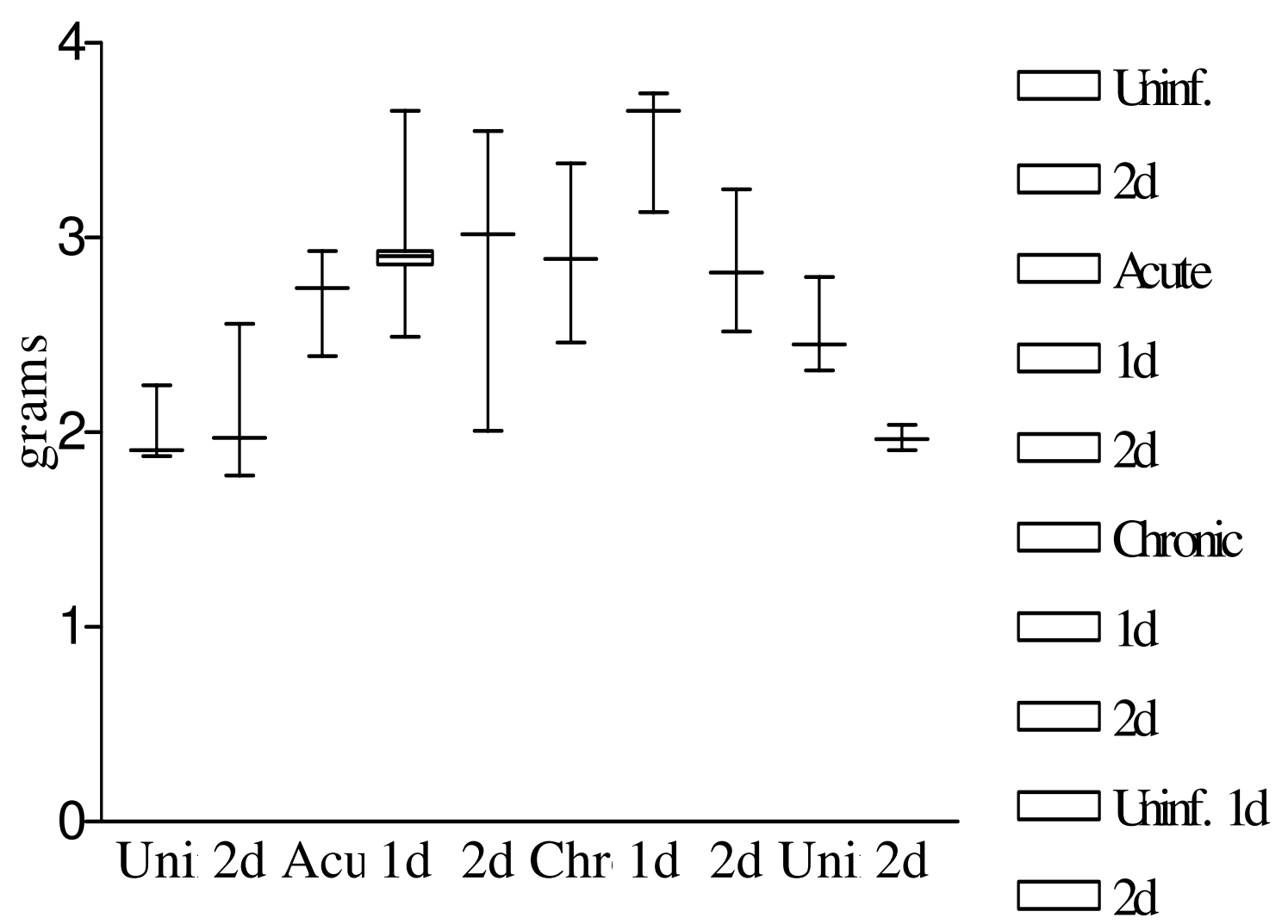

Figure 3

Variations in liver weight after infection and somatostatin treatment. Figure shows the variations in mice liver weights after S. mansoni infection and/or somatostatin treatment. Results are depicted as a box and whiskers plot starting from the left - uninfected mice, uninfected mice with 2 days treatment, 10 weeks infected mice, 10 weeks infected mice with I day treatment, 10 weeks infected mice with 2 days treatment, I 4 weeks infected mice, I4 weeks infected mice with I day treatment, I4 weeks infected mice with 2 days treatment. Values represent the $5^{\text {th }}, 25^{\text {th }}, 50^{\text {th }}, 75^{\text {th }}$ and $95^{\text {th }}$ percentiles.

vacuum pump and thereafter washed thrice more with $6 \mathrm{~N}$ $\mathrm{HCl}$. The residue was rewashed with 95\% ethanol and 100 $\%$ ethanol, and the powder dried over several days.

2. Solution A: One part $7 \%$ chloramine T-solution (Sigma) was mixed with 4 parts of citrate/acetate buffer (pH 6.0: $57 \mathrm{~g}$ sodium acetate $3 \mathrm{H}_{2} \mathrm{O}$ (Merck) + $37.5 \mathrm{~g}$ Na3citrate. $2 \mathrm{H}_{2} \mathrm{O}$ (Sigma) +5.03 g Citrate $+385 \mathrm{ml}$ isopropanol made up to 1 liter with distilled water).

3. Solution B: Composed of 3 parts of Ehrlichs reagent (25 g p-dimethyl amino benzal dehyde (Sigma) dissolved in $37.5 \mathrm{ml} \mathrm{60 \%}$ perchloric acid) and 13 parts isopropanol.

4. Hydroxyproline standard solution: $6.56 \mathrm{mg}$ hydroxyproline standard (Merck) dissolved in $500 \mathrm{ml}$ gave a 0.1 $\mathrm{mM}$ hydroxyproline-solution. This solution remains sta- ble at $4{ }^{\circ} \mathrm{C}$ thereby enabling us to set up a standard curve of known hydroxyproline values.

\section{Hydrolysis of liver}

For the measurement of the hydroxyproline content in the liver, about $200 \mathrm{mg}$ of liver was treated with $5 \mathrm{ml}$ of $6 \mathrm{~N}$ $\mathrm{HCl}$ for 18 hours at $110^{\circ} \mathrm{C}$. This acidic hydrolysis breaks down the collagen to individual amino acids. Remaining undissolved matter was removed by adding $40 \mathrm{mg}$ Dowex/Norit in $5 \mathrm{ml}$ of distilled water. After centrifugation for 15 minutes at $2000 \mathrm{rpm}$, the supernatant was filtered with the aid of $0.22 \mu \mathrm{m}$ millipore filters (Millipore S.A., Molsheim, France).

\section{Neutralization}

Two $\mathrm{ml}$ of hydrolysate was pipetted out to which was added 1 drop $(40 \mu \mathrm{l})$ of $1 \%$ phenolphthalein. When the 


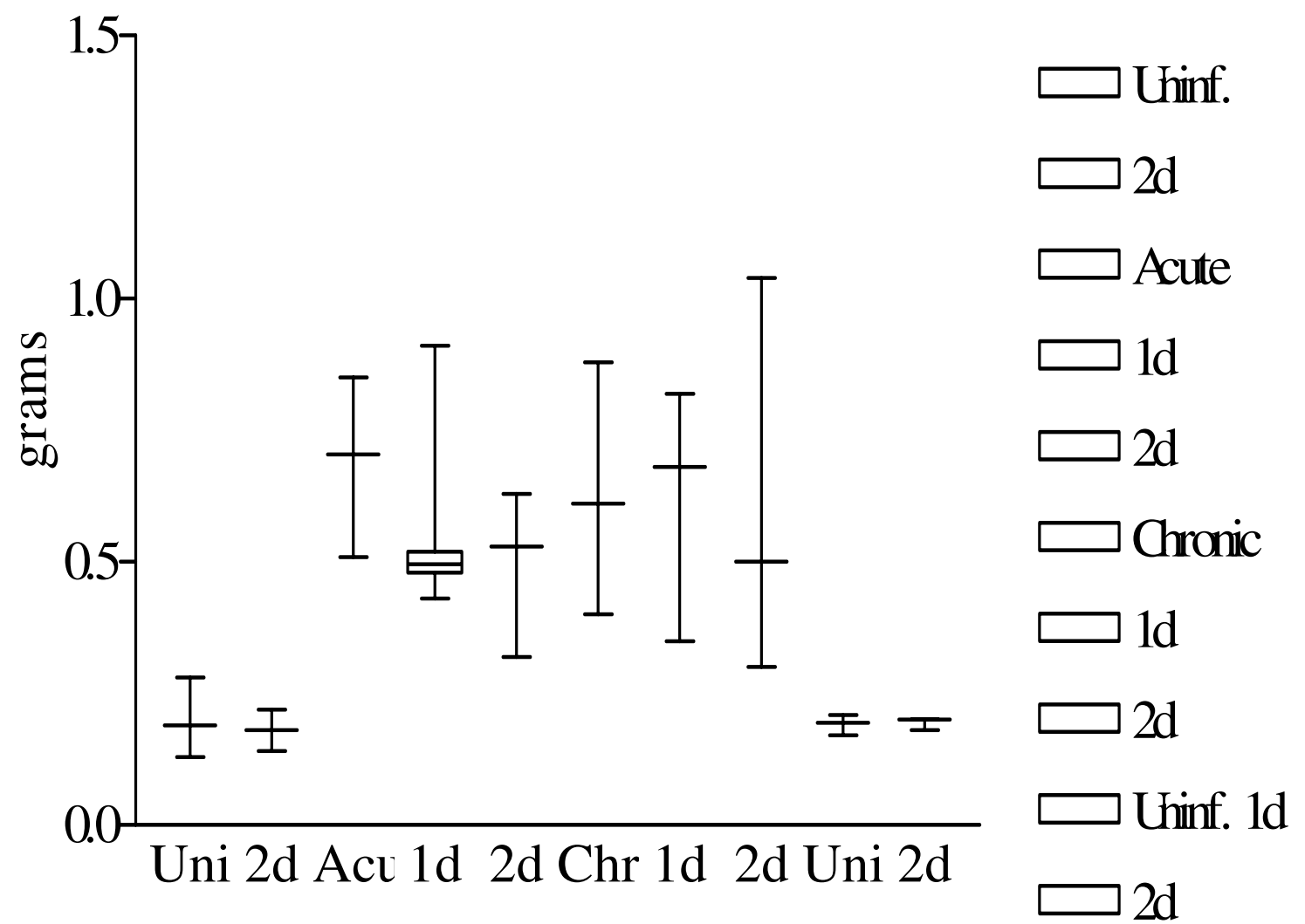

Figure 4

Variations in spleen weight after infection and somatostatin treatment. Figure shows the variations in spleen weight after S. mansoni infection and/or somatostatin treatment. Results are depicted as a box and whiskers plot as mentioned in Fig. 3.

solution became colorless, $10 \mathrm{~N} \mathrm{NaOH}$ was added drop wise till the color changed to purple red. Return titration was done with $5 \mu \mathrm{l}$ drops of a $3 \mathrm{~N} \mathrm{HCl}$ solution, till all red color was lost. The total volume was next restored to $4 \mathrm{ml}$ with distilled water and the solution kept stable at $4{ }^{\circ} \mathrm{C}$.

\section{Color reaction}

Starting from this step we used a series of standard hydroxyproline concentrations made from 0-25-50-75$100 \mu \mathrm{mol} / \mathrm{l}$. (200 $\mu \mathrm{l} /$ test tube). From the test sample above $200 \mu \mathrm{l}$ was placed in a separate test tube. After vortexing $200 \mu \mathrm{l}$ test sample $/ 200 \mu \mathrm{l}$ standard mixed together with $400 \mu \mathrm{l}$ of isopropanol, $200 \mu \mathrm{l}$ of solution A (chloramine $\mathrm{T} /$ citrate-acetate buffer) was added that provided an optimal binding between color and tissue. This reaction needed at least 4 minutes to work after which $2.5 \mathrm{ml}$ of solution B was added and the contents well mixed. The tubes were covered with aluminum foil and incubated for 25 minutes in a warm water bath maintained at $60^{\circ} \mathrm{C}$. To stop the reaction the test tubes were cooled in cold water for 3 minutes.

\section{Measurement}

Within 30 minutes, the absorbance for each sample was measured in an Ultrospec 3000 UV/Visible Spectrofotometer at a wavelength of $558 \mathrm{~nm}$.

\section{Measurement of somatostatin levels in plasma}

The measurement of somatostatin concentrations in the Swiss mice plasma was carried out in the laboratory of Gastro-intestinal Hormones, at Gasthuisberg, K.U. Leuven, by means of a radio-immuno assay (RIA). The RIA was performed by incubating the samples with 1.7 pM 3[125I] iodotyrosyl ${ }^{11}$ somatostatin-14 (specific activity 2000 $\mathrm{Ci} / \mathrm{mmol}$, Amersham Pharmacia Biotech, Buckinghamshire, UK) and a rabbit antibody against human SOM [114 ] in a $50 \mathrm{mM}$ sodium phosphate buffer ( $\mathrm{pH} 7.4,0.25 \%$ EDTA, $0.5 \%$ charcoal-BSA, $500 \mathrm{U} / \mathrm{ml}$ Trasylol) for at least 


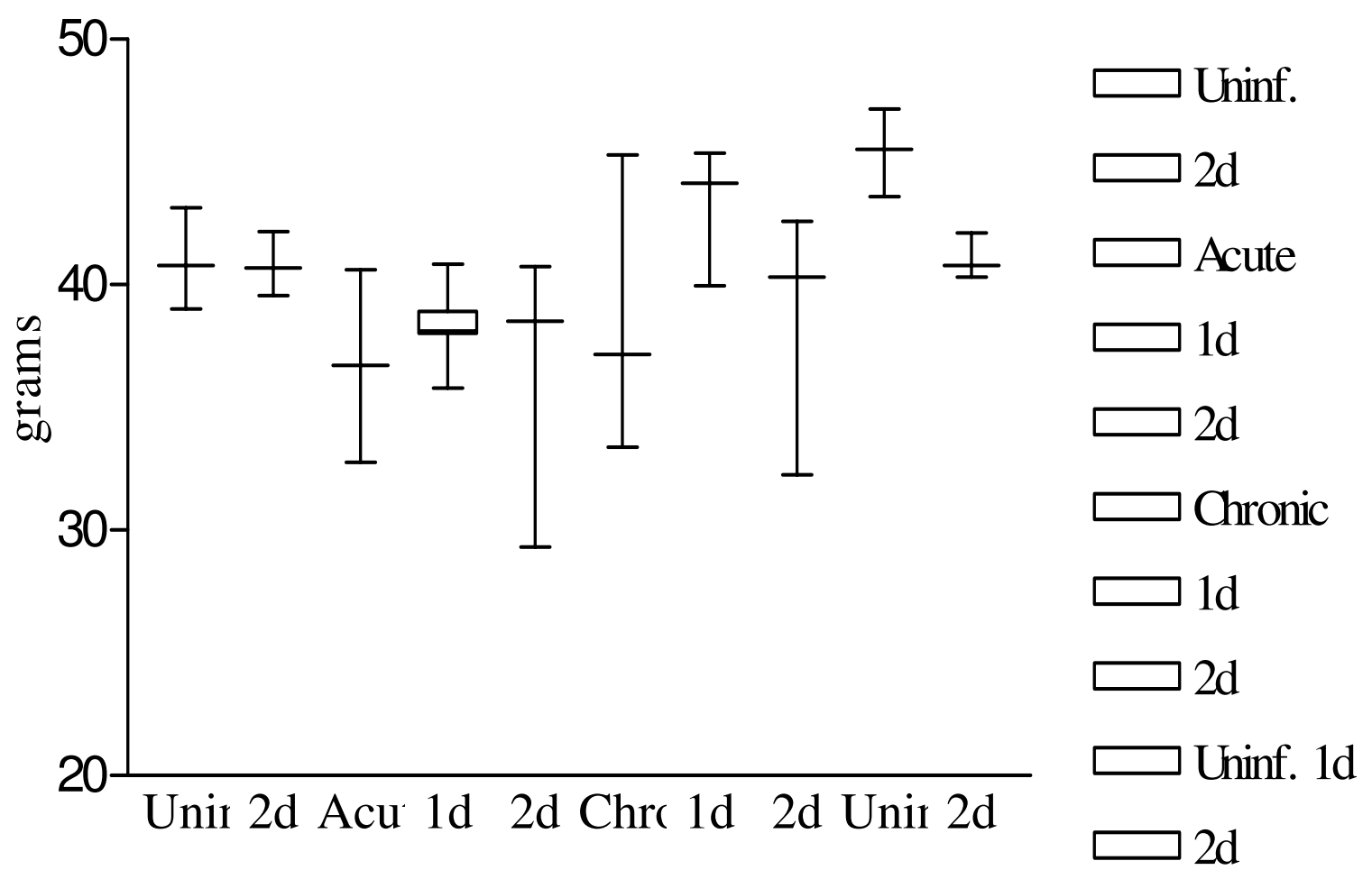

Figure 5

Variations in total body weight after infection and somatostatin treatment. Figure shows the variations in total body weight after S. mansoni infection and/or somatostatin treatment. Results are depicted as a box and whiskers plot as mentioned in Fig. 3.

two days at $4^{\circ} \mathrm{C}$. At the end of the incubation period the SOM bound to the antibody was separated from the free SOM by adding $500 \mu \mathrm{l}$ dextran-charcoal followed by centrifugation for $15 \mathrm{~min}$ at $3000 \mathrm{rpm}$. Both fractions were counted in a gamma counter and the results were read from a standard curve $(0-250 \mathrm{pg} / \mathrm{ml})$ included in the RIA. The minimal detectable dose was $2.5 \mathrm{pg} / \mathrm{ml}$.

\section{Results \\ Toxicity}

Somatostatin is a highly purified compound reflected by the fact that it has very little toxicity. Studies in mice have shown that the LD50 is comparable to 10,000 times the acute therapeutic dose used in humans. The favorable metabolic profile of somatostatin is further supported by the fact that this compound has a very short half-life, and thus any undesirable effects may be rapidly reversed. In our experiment we have used $90 \mu \mathrm{g} / 24$ hours in the Swiss mice that weighs about $40 \mathrm{~g}$. In humans the therapeutic dose is $3.5 \mu \mathrm{g} / \mathrm{kg} /$ hour or $6 \mathrm{mg} / 24 \mathrm{~h}$ for a $75 \mathrm{~kg}$ man. A comparison of these values tells us that we are working with about 100 times higher values in mice as compared to that used in humans.

\section{Pharmacokinetic profile of somatostatin in outbred mice}

Following an intravenous infusion of a therapeutic dose of somatostatin (250 $\mu \mathrm{g} /$ hour or $6 \mathrm{mg} / 24$ hours) to healthy volunteers, the plasma profile demonstrated that the drug reaches a plateau of 300-3000 pg/ml within 15 minutes. Somatostatin has a very short half-life of 1-3 minutes in man. In animal studies the same profile has been observed in dogs, whereas in rats somatostatin is stable for up to 30 minutes in whole blood, indicating that it is broken down in tissues [17]. To determine the pharmacokinetic profile in outbred Swiss mice, $25 \mu \mathrm{g}$ of somatostatin was administered per mouse via the intraperitoneal or intravenous route. To assess the break down in these mice, plasma was collected at regular time intervals and circulating somatostatin levels assayed (Figure 2). At 10 minutes post injection somatostatin levels fall to $30233 \mathrm{pg} / \mathrm{ml}$ (IP) and $17413 \mathrm{pg} / \mathrm{ml}$ (IV). After intravenous injection thus somatostatin appears to be more 


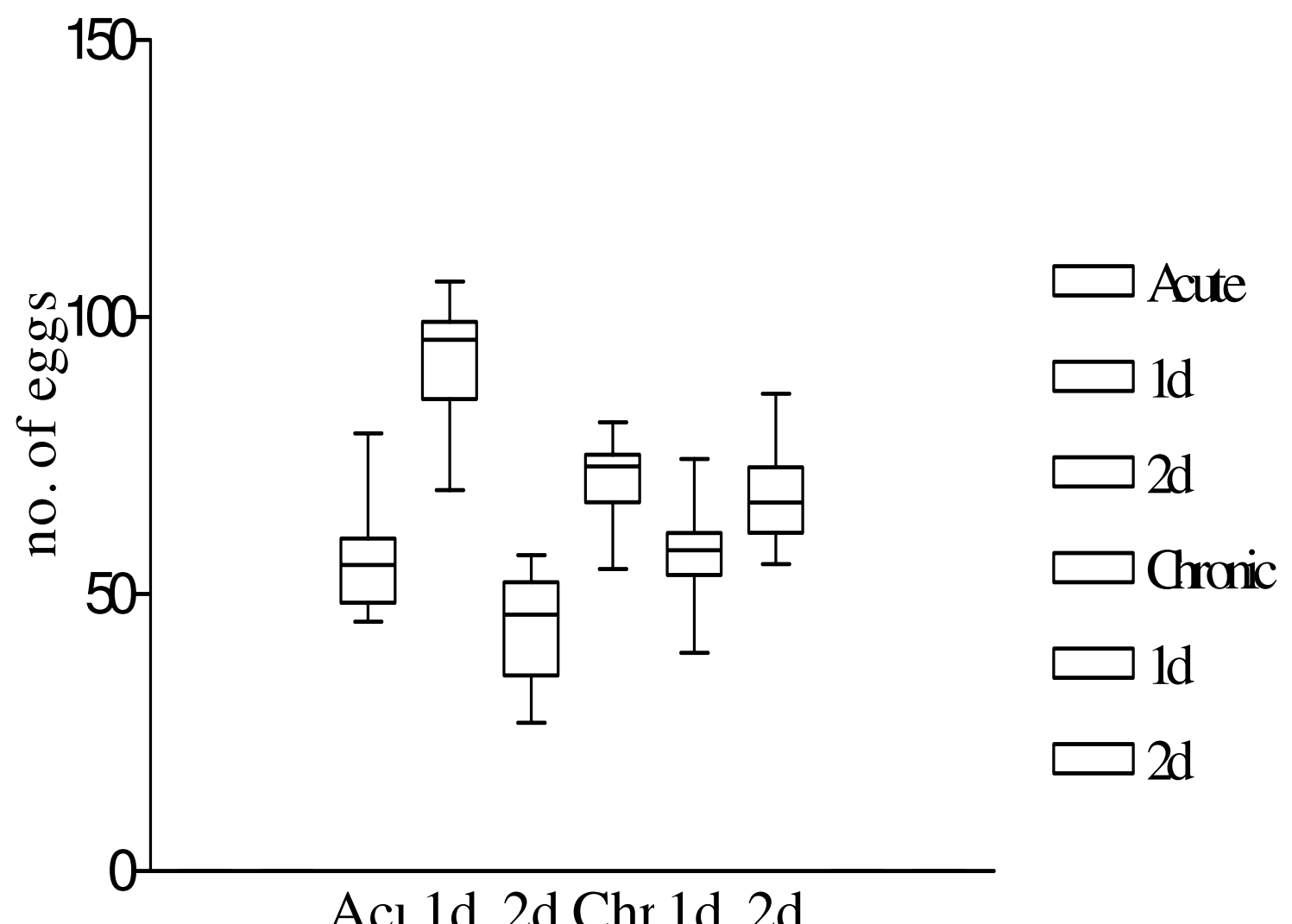

\section{Figure 6}

Variations in parasite egg count after somatostatin treatment. Figure shows the variations in parasite egg count after somatostatin treatment. Box and whiskers plot depicting the $5^{\text {th }}, 25^{\text {th }}, 50^{\text {th }}, 75^{\text {th }}$ and $95^{\text {th }}$ percentiles represent egg counts at 10 weeks of infection, variations after I day of treatment or 2 days of treatment, egg counts at I4 weeks of infection, variations after I day or 2 days of treatment.

rapidly degraded than after intraperitoneal injection, however after one hour of injection using either means the levels of circulating somatostatin in blood reaches baseline control levels. Thus in our experimental set up of somatostatin treatment in S. mansoni infected mice the schedule of 3 treatments per day (morning, noon and evening), assured that for at least 3 hours per day there were significantly high levels of circulating somatostatin in vivo.

\section{Body and Organ weight after somatostatin treatment}

The weight of the liver increased with infection, with a significant rise at the acute $(\mathrm{p}=0.01)$ and chronic stage $(\mathrm{p}=$ 0.01 ) as compared to the uninfected animals (Fig. 3.). Acute and chronic infected animals after 2 days of somatostatin treatment showed no significant change in their liver weights ( $\mathrm{p}=0.19 ; 0.90$ respectively).

Mean spleen weights were significantly increased in acute $(\mathrm{p}=0.01)$ and chronic $(\mathrm{p}=0.01)$ infected animals as compared to uninfected controls (Fig. 4.). Acute and chronic infected animals after 2 days somatostatin treatment showed no significant changes in their spleen weights ( $\mathrm{p}=0.28 ; 0.73$ respectively).

The total body weight of the acute infected animals showed a decrease as compared to uninfected animals however this difference was borderline significant ( $\mathrm{p}=$ 0.06) (Fig. 5). There were no significant changes in body 


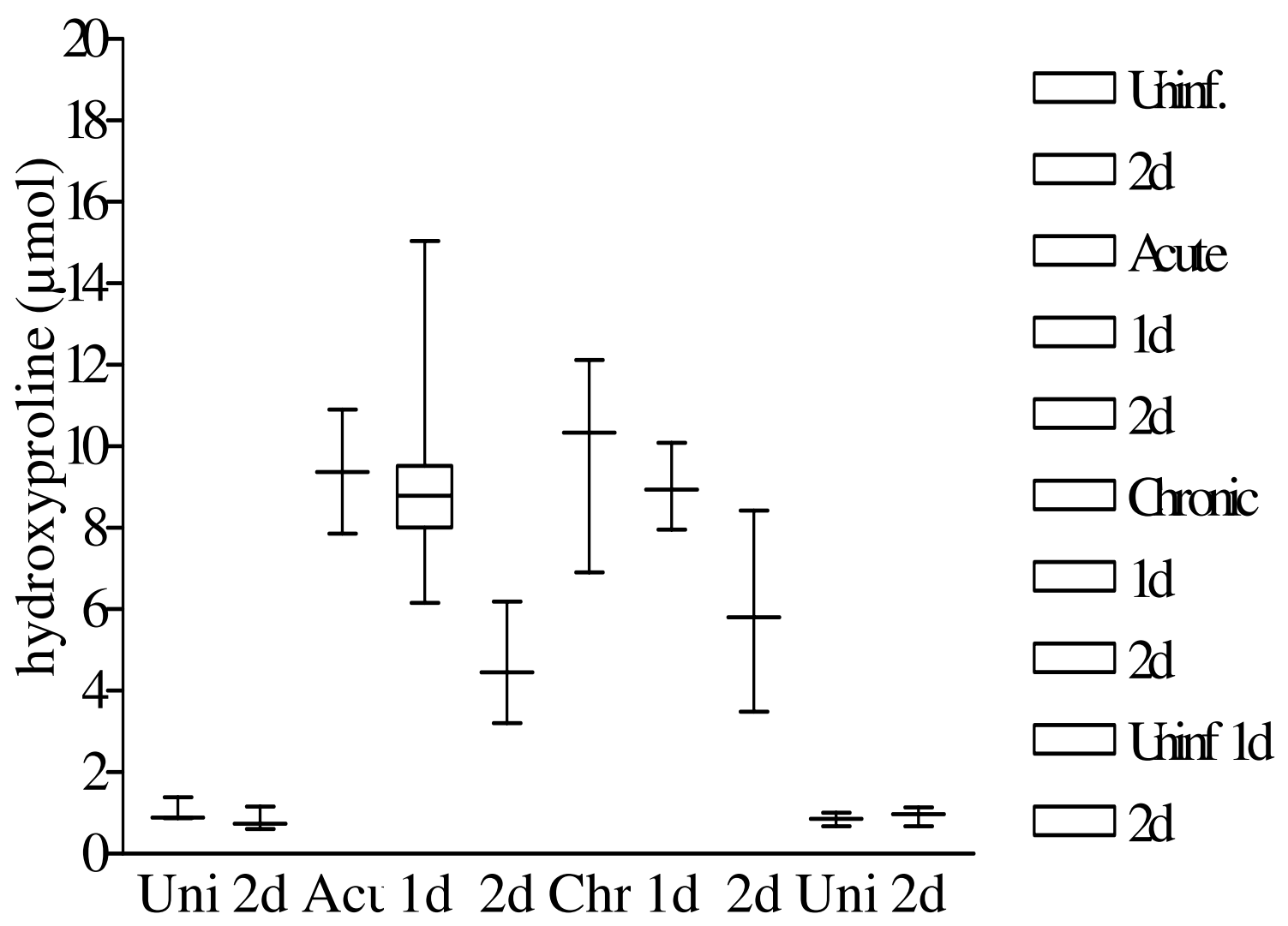

\section{Figure 7}

Hydroxyproline levels after somatostatin treatment. Figure depicts the hydroxyproline levels after S. mansoni infection and/or somatostatin treatment. Values are represented as a box and whiskers plot as described in Fig. 3.

weight in acute or chronic infected animals after somatostatin treatment.

\section{Parasite egg count after somatostatin treatment, hepatocyte, granuloma and fibrosis status}

S. mansoni egg stage parasites were counted in liver sections before and after somatostatin treatment. A series of 10 slides were examined from each sub group, the sections obtained at intervals of at least $40 \mu \mathrm{m}$ so as to avoid counting repetitive eggs. Two days of somatostatin treatment in acute infected animals significantly reduced the mean parasite egg counts form $56.01 \pm 3.34$ to $43.76 \pm$ $3.56(\mathrm{p}=0.03)$. At the chronic stage of infection, mean egg counts were only significantly $(p=0.006)$ reduced after 1 day of somatostatin treatment from $69.82 \pm 2.77$ to $56.62 \pm 3.02$ (Fig. 6.).
Haematoxylin-eosin staining of liver sections displayed the evolution of granuloma formation in infected animals as compared to treated animals. After treatment with somatostatin hepatocyte status remained unaltered, granulomas were not remarkably changed in size or cellularity (results not shown).

\section{Hydroxyproline determination}

Hepatic fibrosis is the process of excessive deposition of collagen in the liver. Collagen generation involves 3 polypeptide chains, each chain composed of 19 amino acids consisting of glycine $(30 \%)$, proline $(12 \%)$ and two other rather uncommon amino acids - hydroxyproline (10\%) and to an even lesser extent hydroxylysine. Proline and hydroxyproline are responsible for the angle (kink) in the polypeptide backbone furthermore hydroxyproline stabilizes the collagen via intramolecular hydroxyl 
Table 2: The hydroxyproline values calculated in the different groups.

\begin{tabular}{|c|c|c|c|}
\hline & Group I & Group 2 & Group I vs. Group 2 \\
\hline No SOM treatment & $\begin{array}{l}\text { Uninf:: } 1.06 \pm 0.10 \\
\text { Acute: } 9.37 \pm 0.63 \\
\text { p-value: } \mathbf{0 . 0 1} * *\end{array}$ & Chronic: $9.65 \pm 0.96$ & $\begin{array}{l}\text { Uninf:: } 1.06 \pm 0.10 \\
\text { Chronic: } 9.65 \pm 0.96 \\
\text { p-value: } \mathbf{0 . 0 0 7} * * \\
\text { Acute: } 9.37 \pm 0.63 \\
\text { Chronic: } 9.65 \pm 0.96 \\
\text { P-value: } 0.90 \text { (NS) }\end{array}$ \\
\hline I day SOM treatment & Acute: $9.37 \pm 1.24$ & $\begin{array}{l}\text { Uninf.: } 0.85 \pm 0.08 \\
\text { Chronic: } 8.99 \pm 0.61 \\
\text { p-value: }<0.0001^{* * *}\end{array}$ & $\begin{array}{l}\text { Acute: } 9.37 \pm 1.24 \\
\text { Chronic: } 8.99 \pm 0.61 \\
\text { P-value: } 0.90(\mathrm{NS})\end{array}$ \\
\hline 2 day SOM treatment & $\begin{array}{l}\text { Uninf.: } 0.81 \pm 0.09 \\
\text { Acute: } 4.76 \pm 0.58 \\
\text { p-value: } 0.007 * * \\
\text { Acute (untreated): } 9.37 \pm 0.63 \\
\text { Acute (2d SOM): } 4.76 \pm 0.58 \\
\text { p-value: } 0.01 * *\end{array}$ & $\begin{array}{l}\text { Uninf.: } 0.93 \pm 0.09 \\
\text { Chronic: } 5.88 \pm \mathrm{I} .13 \\
\text { p-value: } \mathbf{0 . 0 2 *} \\
\text { Chronic (untreated): } 9.65 \pm 0.96 \\
\text { Chronic (2d SOM): } 5.8 \pm 1.13 \\
\text { p-value: } \mathbf{0 . 0 3 *}\end{array}$ & $\begin{array}{l}\text { Uninf. (I } 7 \text { wks.): } 0.8 \mathrm{I} \pm 0.09 \\
\text { Uninf. (2I wks.): } 0.93 \pm 0.09 \\
\text { P-value: } 0.4 \mathrm{I}(\mathrm{NS}) \\
\text { Acute: } 4.76 \pm 0.58 \\
\text { Chronic: } 5.88 \pm 1.13 \\
\text { P-value: } 0.4 \mathrm{I} \text { (NS) }\end{array}$ \\
\hline
\end{tabular}

SOM: somatostatin; Uninf.: uninfected; Inf.: infected; Wks.: weeks; *Significant difference $(p<0.05)$; ** significant difference $(p<0.01)$; NS: not significant difference

bridges. Normal hydroxylated collagen is equivalent to $10 \%$ hydroxyproline in weight. Thus $1 \mu \mathrm{mol}$ hydroxyproline $(\mathrm{MW}=131.13)$ is equivalent to $1.3113 \mathrm{mg}$ collagen. Hydroxyproline concentrations in the livers (controls versus acute, chronic, treated and untreated) of the Swiss mice are depicted in Table 2 and figure 7 . The differences in hydroxyproline concentrations between uninfected and infected mice with or without treatment are illustrated by non-parametric (Mann-Whitney U) or parametric (unpaired Student's t) test as shown in Table 2.

At 10 weeks post infection with 100 S. mansoni cercariae, levels of hydroxyproline were significantly higher as compared to that assayed in uninfected animals $(\mathrm{p}=0.01)$ (Fig. 7.). After treatment with somatostatin for 2 days, circulating levels of this collagen at one-week post treatment time were significantly lower as compared to infected animals that were not treated $(\mathrm{p}=0.01)$.

Progression of the infection from week 10 to week 14 did not result in a significant rise in hydroxyproline levels. Treatment of chronically infected animals with a two-day regimen of exogenous somatostatin resulted in a drop in hydroxyproline levels at one-week post treatment. This fall was significant $(\mathrm{p}=0.03)$ as compared to chronic untreated animals.

\section{Somatostatin levels}

Somatostatin concentrations in the plasma (controls versus acute, chronic, treated and untreated) of the Swiss mice are depicted in Table 3 and figure 8 . The differences in somatostatin concentrations between uninfected and infected mice with or without treatment were illustrated by a non-parametric (Mann-Whitney U) test as shown in Table 3. The distribution of somatostatin levels in all groups is depicted in Figure 8. At 10 weeks post infection with $100 \mathrm{~S}$. mansoni cercariae, levels of circulating somatostatin were significantly higher as compared to that assayed in uninfected animals $(p=0.01)$. After treatment with somatostatin for 1 or 2 days, circulating levels of this neuropeptide at one week post treatment time were not significantly different as compared to infected animals that were not treated.

Progression of the infection from acute (week 10) to chronic (week 14) stages resulted in a drop in the somatostatin levels. Comparison of somatostatin levels between these two time points depicted borderline significant differences $(p=0.06)$. Treatment of chronically but not of acute infected animals with a two-day regimen of exogenous somatostatin resulted in an elevated level of circulating hormone at one-week post treatment. This rise in circulating somatostatin level was borderline significant $(\mathrm{p}=0.06)$ as compared to chronic untreated animals.

\section{Discussion and conclusions}

The neuropeptide somatostatin is one of the major regulatory hormones in the central nervous system and the digestive tract. Improved knowledge of the patho-physiological processes of schistosomiasis can be obtained by studying the regulatory mechanisms of somatostatin in the human body. The activity of somatostatin is mediated 
Table 3: The somatostatin levels calculated in the different groups.

\begin{tabular}{|c|c|c|c|}
\hline & Group I & Group 2 & Group I vs. Group 2 \\
\hline No SOM treatment & $\begin{array}{l}\text { Uninf.: } 119.4 \pm 11.99 \\
\text { Acute: } 297.3 \pm 37.24 \\
\text { p-value: } 0.01 * *\end{array}$ & Chronic: $206.1 \pm 13.30$ & $\begin{array}{l}\text { Uninf.: II9.4 } \pm \text { II } .99 \\
\text { Chronic: } 206.1 \pm 13.30 \\
\text { p-value: } 0.008 * * \\
\text { Acute: } 297.3 \pm 37.24 \\
\text { Chronic: } 206.1 \pm 13.30 \\
\text { p-value: } \mathbf{0 . 0 6} \text { (BL) }\end{array}$ \\
\hline I day SOM treatment & Acute: $240.3 \pm 21.30$ & $\begin{array}{l}\text { Uninf:: }|3| .6 \pm 19.34 \\
\text { Chronic: } 226.3 \pm 5.4 \mid \\
\text { p-value: } \mathbf{0 . 0} \mid * *\end{array}$ & $\begin{array}{l}\text { Acute: } 240.3 \pm 21.30 \\
\text { Chronic: } 226.3 \pm 5.41 \\
\text { P-value: } 0.71 \text { (NS) }\end{array}$ \\
\hline 2 day SOM treatment & $\begin{array}{l}\text { Uninf.: } 136.9 \pm 11.69 \\
\text { Acute: } 234.2 \pm 23.65 \\
\text { p-value: } 0.008 * * \\
\text { Acute (untreated): } 297.3 \pm 37.24 \\
\text { Acute (2d SOM): } 234.2 \pm 23.65 \\
\text { P-value: } 0.28\end{array}$ & $\begin{array}{l}\text { Uninf.: } 151.6 \pm 41.45 \\
\text { Chronic: } 247.9 \pm 13.1 \mathrm{I} \\
\text { P-value: } 0.1 \mathrm{I}(\mathrm{NS}) \\
\text { Chronic (untreated): } 206.1 \pm 13.30 \\
\text { Chronic (2d SOM): } 247.9 \pm 13.1 \mathrm{I} \\
\text { p-value: } \mathbf{0 . 0 6} \text { (BL) }\end{array}$ & $\begin{array}{l}\text { Uninf. ( } 17 \text { wks.): } 136.9 \pm 11.69 \\
\text { Uninf. }(2 \mid \text { wks.): } 151.6 \pm 41.45 \\
\text { P-value: } 0.9(\mathrm{NS}) \\
\text { Acute: } 234.2 \pm 23.65 \\
\text { Chronic: } 247.9 \pm 13.1 \mathrm{I} \\
\text { P-value: } 0.73(\mathrm{NS})\end{array}$ \\
\hline
\end{tabular}

SOM: somatostatin; Uninf.: uninfected; Inf.: infected; Wks.: weeks;

* Significant difference $(p<0.05)$; ** significant difference $(p<0.0 \mathrm{I})$; BL: borderline significant difference; NS: not significant difference

via binding to specific cell surface receptors. To understand the expression, regulation, true role and distribution of these receptors, animal models come in helpful in defining the physiological and pathological conditions set up by schistosomiasis. Somatostatin, produced by neuroendocrine, inflammatory and immune cells inhibits various cellular functions including secretions, motility, and proliferation $[18,13]$. Preprosomatostatin (pp-SOM), a precursor of somatostatin is synthesized in the pancreas, the gastrointestinal network, and the brain. Two products of this pp-SOM are somatostatin-14, a 14 amino acid peptide, and somatostatin-28 (SS-28) that contain the SS-14 but is prolonged at the $\mathrm{N}$-terminus. Its action is mediated by five specific somatostatin receptors (SSTR1 - SSTR5), which belong to the $\mathrm{G}$ protein-coupled receptor family.

The last years we have been studying the potential of somatostatin in modulating the pathology caused by schistosomiasis, in particular hepatic fibrosis. The trematode, Schistosoma mansoni is phylogenetically the oldest class of invertebrate in which we have identified immunopositivity to the somatostatin receptors SSTR2 and SSTR3 (manuscript submitted). The presence of these receptors on the parasite stages indicate that circulating somatostatin levels might interact with the pathogenic parasitic stages and hence influence hepatic fibrosis caused by this parasite.

The helminth parasite Schistosoma mansoni and its related species cause the fibrotic hepatic disease, schistosomiasis. Fibrosis is the process of excessive deposition of collagen in a tissue together with other extracellular matrix (ECM) components like fibronectin, proteoglycans, laminin and elastin. To some extent ECM deposition is necessary for wound healing since it provides strength and temporary structure to damaged tissues. However, if not limited this process is pathogenic. Liver fibrosis can be particularly detrimental leading to portal hypertension and its attendant sequelae that include splenomegaly and rupture-prone gastroesophageal varices.

The collagen peptide-synthesis in the liver of infected mice attains a peak activity at 8 weeks post infection. The triple polypeptide chains, assembled to form procollagen, once leaving the cell come together to form polymeric collagen fibers. The hydroxyproline residues take care of the stability of the three dimensional helix via the formation of hydroxyl bridges between the polypeptide chains. The important points in collagen biosynthesis are thus the positioning of the hydroxylproline residues in the triple backbone structure, the knipping off of the propeptides from procollagen to form collagen as it leaves the cell and finally the cross-linking to form fibers. The deposition of fibronectin and heparansulphate round the egg rises rapidly till week 11 post infection after which levels plateau off. All these extracellular matrix components interact with different cells and modulate various cellular activities like migration, proliferation, differentiation, chemotaxis etc. [19].

Somatostatin that has earned itself the nickname 'endocrine cyanide' due to its slowing down a number of 


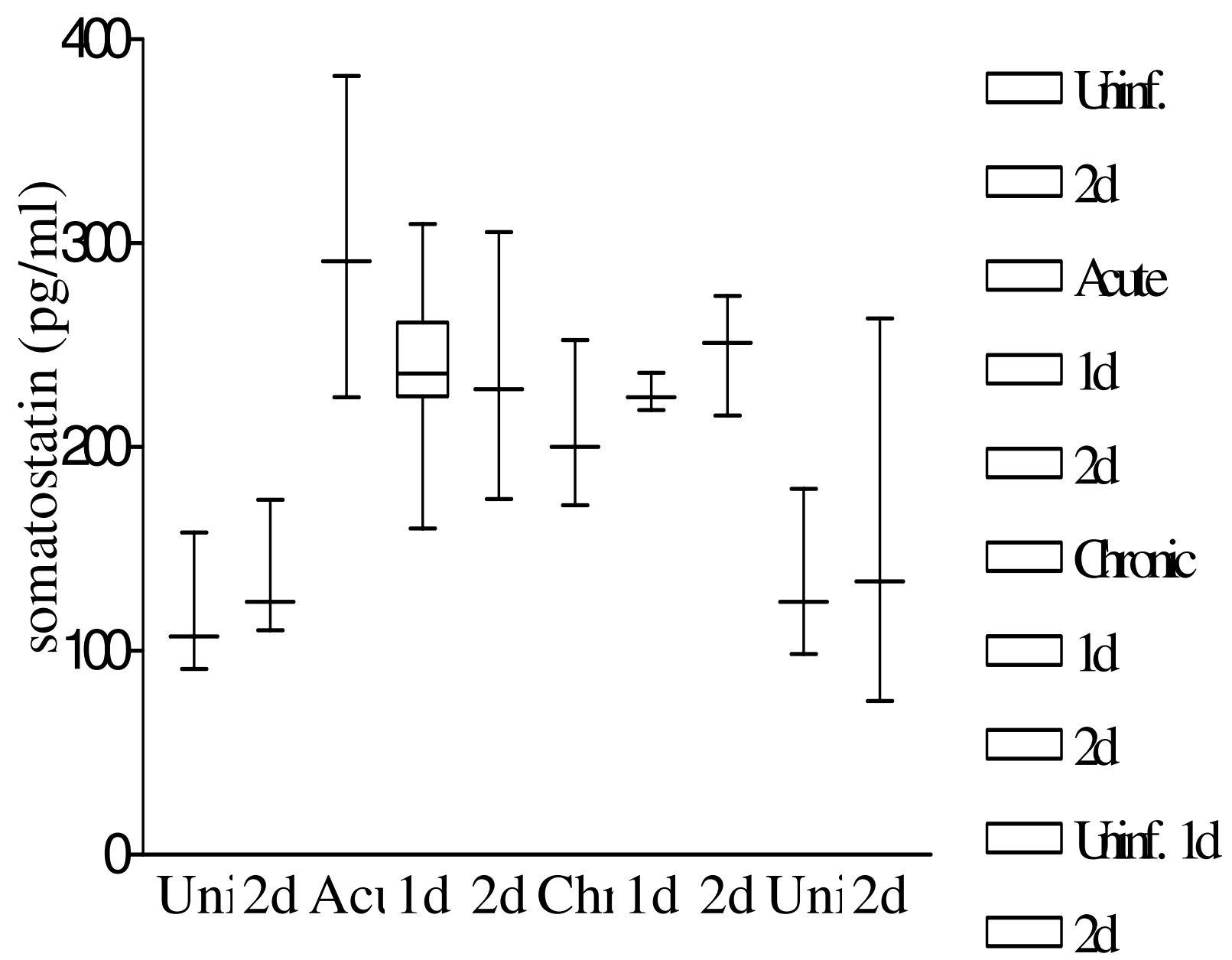

\section{Figure 8}

Somatostatin levels after infection and therapy. Figure shows a box and whiskers plot depicting somatostatin values after $\mathbf{S}$. mansoni infection and/or somatostatin therapy. Results are described as in Fig. 3.

biological processes in the body, might add another feature to its ubiquitous nature - that of reducing fibrosis in Schistosoma mansoni infections.

We have quantified fibrosis (amount of collagen) generated by $S$. mansoni infections and the reductions after somatostatin treatments by measuring the levels of hydroxyproline at each time point.

In acute and chronic infected animals that were untreated, the increased collagen levels were associated with increased somatostatin levels respectively. Two days treatment of acute and chronic infected animals with somatostatin significantly reduced hydroxyproline levels.
Endogenous somatostatin levels were not affected during the acute phase after somatostatin treatment although in chronic infected mice endogenous somatostatin levels tended to increase. However, at both time points, a significant reduction in parasite egg counts was observed, suggesting that therapeutic doses of somatostatin might, by binding to somatostatin receptors on the parasite surface, inhibit the production of the parasite stage that induces the inflammatory granulomatous response that can lead to fibrosis.

Reports by Reynaert et al. [12] have identified the somatostatin receptors SSTR1, 2 and 3 on the hepatic stellate cells that are responsible for collagen synthesis. In our 
experiments exogenous somatostatin might also have bound to these receptors thereby inhibiting collagen synthesis.

Taken together we have elucidated the therapeutic capacity of somatostatin in reducing hepatic fibrosis. This report in fact confirms a previous report by Mansy [20], where using a somatostatin synthetic analog octreotide in $S$. mansoni infected animals, a reduction in hepatic fibrosis was noted. Since octreotide is limited in binding to somatostatin receptors, our results with natural somatostatin that binds to all 5 somatostatin receptors equally well assures us of the anti fibrotic capacities of this neuropeptide hormone, and points to its potential use in human conditions.

\section{Competing interests}

The author(s) declare that they have no competing interests.

\section{Authors' contributions}

SC designed this study, performed the parasite egg counting, and statistical analysis. GV carried out the animal infection, somatostatin treatment, and hydroxyproline determinations. IDP and TP performed the somatostatin detection in the mice plasma. EVM participated in the design of the study and coordination. All authors read and approved the final manuscript.

\section{Acknowledgements}

The authors wish to thank Mr. Michel Segers, UCB Pharma, Brussels, for the kind gift of somatostatin ${ }^{\circledR}$ that was used in all experiments. This work was supported by the Inter-University Attraction Program (Grants P4/16 and P5/20) Services of the Prime Minister Federal Agency for Scientific, Technical and Cultural Affairs. The contribution of Kristel Kuypers and Koen Van de Vijver in the standardization of the hydroxyprolene procedure is much appreciated. Many thanks to Frank Rylant and Liliane Moeneclaey for the cryo-sectioning and staining of liver samples.

\section{References}

I. Chatterjee S, Mbaye A, Alfidja AT, Weyler J, Scott JT, Van Damme P, Van De Vijver K, Deelder A, Van Marck EAE: Circulating levels of the neuropeptide hormone somatostatin may determine hepatic fibrosis in Schistosoma mansoni infections. Acta Trop 2004, 90:191-203.

2. Avgerinos A, Nevens F, Raptis S, Fevery J: Early administration of somatostatin and efficacy of sclerotherapy in acute oesophageal variceal bleeds: the European acute bleeding oesophageal variceal episodes (ABOVE) randomized trial. Lancet 1997, 350:1495-1499.

3. Lin HJ, Perng CL, Lee FY, Lee CH, Lee SD: Clinical courses and predictors for rebleeding in patients with peptic ulcers and non-bleeding visible vessels: a prospective study. Gut 1994, 35:1389-1393.

4. Bordas JM, Toledo-Pimentel V, Llach J, Elena M, Mondelo F, Gines A, Teres $\mathrm{J}$ : Effects of bolus somatostatin in preventing pancreatitis after endoscopic pancreatography: results of a randomized study. Gastroint Endosc 1988, 47:230-234.

5. Borda F, Jimenez FJ, Villa J: Cost-effectiveness study on the use of somatostatin for reduction of acute pancreatitis after ERCP. Gastroentero Hepatol 200I, 24:292-296.
6. Cicero GF, Laugier R, Sahel J, Manganaro M, Sarles H: Effects of somatostatin on clinical, biochemical and morphological changes following ERCP. Int J Gastroenterol 1985, 17:265-268.

7. Cheever AW: Quantitative comparison of the intensity of Schistosoma mansoni infection in man and experimental animals. Trans R Soc Trop Med 1969, 63:781-795.

8. Andrade ZA, Grimaud J-A: Morphology of chronic collagen resorption (a study on the late stages of schistosomal granuloma involution. Am J Path 1988, 132:389-399.

9. Grimaud J-A: Cell-matrix interactions in schistosomal portal fibrosis: a dynamic event. Mem Inst Oswaldo Cruz 1987, 82:55-65.

10. Da Silva LC, Mourao PA, Borojevic R: Patterns of sulfated glycosaminoglycan synthesis and accumulation in hepatic granulomas induced by Schistosomal infection. Exp Mol Pathol 1989, 50:4I I-420.

II. Van Marck EA, Stocker S, Grimaud JA, Kestens L, Gigase PL, Deelder AM: The implantation of sepharose beads in mouse livers as an aid in the study of hepatic schistosomal fibrosis. Experientia 1980, 36: III6-III8.

12. Reynaert H, Vaeyens F, Rombouts K, Chatterjee N, Urbain D, Geerts A: Effect of somatostatin- 14 on extracellular matrix expression by activated rat hepatic stellate cells. J Hepatol 200I, 34:6.

13. Chatterjee S, Mbaye A, De Man J, Van Marck E: Does the neuropeptide somatostatin have a therapeutic role in schistosomiasis? Trends Parasitol 2002, 18:295-298.

14. Van Marck EAE: The glomerulopathy associated with Schistosoma mansoni infection. An experimental study in the mouse. Acta Leidensia 1983, 50:.

15. Bergman I, Loxley R: Two improved and simplified methods for spectrophotometric determination of hydroxyproline. Analyt Chem 1963, 35:| $96 \mid-1965$.

16. Cheever AW, Duvall RH, Hallack TA Jr, Minker RG, Malley JD, Malley KG: Variations of hepatic fibrosis and granuloma size among mouse strains infected with Schistosoma mansoni. Am J Trop Med Hyg 1987, 37:85-97.

17. Peters GE: Distribution and metabolism of exogenous somatostatin in the rat. Reg Pept 1982, 3:361-369.

18. Peeters TL, Janssens J, Vantrappen GR: Somatostatin and the interdigestive migrating motor complex in man. Reg Pept 1983, 5:209-217.

19. Nishimura MO, Asahi M, Hayashi M, Takazono I, Tanaka Y, Kohda H, Urabe $\mathrm{H}$ : Extracellular matrix in hepatic granulomas of mice infected with Schistosoma mansoni (qualitative and quantitative analysis). Arch Path Lab Med 1985, 109:8I3-8I8.

20. Mansy SS, Yehia HA, Hassan MM, Hassan EA, Youssef MM, Hadi AA Mackenzie CD: Effect of octreotide on the pathology of hepatic schistosomiasis. Arzneimittelforschung 1998, 48:855-861.

\section{Pre-publication history}

The pre-publication history for this paper can be accessed here:

http://www.biomedcentral.com/1471-2334/5/45/prepub

Publish with Biomed Central and every scientist can read your work free of charge

"BioMed Central will be the most significant development for disseminating the results of biomedical research in our lifetime. "

Sir Paul Nurse, Cancer Research UK

Your research papers will be:

- available free of charge to the entire biomedical community

- peer reviewed and published immediately upon acceptance

- cited in PubMed and archived on PubMed Central

- yours - you keep the copyright
BioMedcentral 